This article has been accepted for publication in Child and Family Social Work, published by Wiley. Please cite as:

Whincup $\mathrm{H}$ What do social workers and children do when they are together? A typology of direct work (Forthcoming/Available Online), Child and Family Social Work. 


\title{
What do social workers and children do when they are together? A typology of direct work
}

\begin{abstract}
There is renewed interest in the place of direct work and relationship-based practice in social work. This paper explores the day-to-day direct work which happens where children and young people are 'looked after' at home, from the perspectives of children, social workers and those supervising practice. It is based on interviews with eight children and twenty-five professionals about their experiences. In this paper, I highlight that despite barriers, direct work which is characterised as meaningful by children and professionals happens; and that the relationships formed between children and social workers are an important precursor to, and an outcome of direct work. The research was undertaken in Scotland, and although the legislation, policy and guidance differs from other jurisdictions, the messages about direct work are relevant for practice in other countries.
\end{abstract}

Key words: Direct work, Relationship, Typology of work

\section{Introduction}

Although there are common principles, including an ambition to keep the child's needs at the centre, legislation and policy underpinning social work intervention with children and young people ${ }^{1}$ varies between different countries. In Scotland, the primary relevant legislation currently is the Children (Scotland) Act 1995 and the Children's Hearings (Scotland) Act 2011. Both set out that, where a child's needs may be compromised, s/he can be referred to the Reporter to the Children's Hearing. Where concerns are sufficient to warrant possible statutory intervention the Reporter can arrange a Children's Hearing. The Hearing system is based on the principle that the child's welfare is the paramount consideration. One disposal open to a Children's Hearing is to place a child on a Compulsory Supervision Order at home, which essentially means they become 'looked after' at home. While there is some research with this group of children (Gadda 2012; Henderson and Whitehead 2013), despite forming approximately a third of all looked after children (SCRA 2015), their experiences have been less documented (Tarara and Daniel 2007) compared with those children who are looked after and accommodated away from home.

There is growing interest in the UK in the role which direct work does, should, or could play in social work practice with children (Lefevre 2008). In her final report on the child protection system in England, Munro stated that "above all (my italics) it is important to work directly with children and young people" (2011, p87). However, while there is a long history of direct work in social work practice (Butler and Williamson 1994) and policy documents include statements which imply, directly or obliquely, that direct work is a 'good thing', most omit to explicitly consider what this comprises. In Scotland, Changing Lives (Scottish Executive 2006) employed the term 'casework', rather than direct work, but did not detail what this might include. Similarly, in their research on how social workers (in England) spent their time, Baginsky et al. (2010) referred to 'face to face direct work' but identified what this excluded, rather than what it included. With some exceptions (Tait and Wosu 2013, 2016:

\footnotetext{
${ }^{1}$ For brevity 'children and young people' will be shortened to 'children'
} 
Emond et al. 2016) there has been a focus on the barriers to direct work, and what practitioners are not doing, rather than a spotlight on what it might look like and what is happening. Moreover, although children's experiences of being involved, or not, in decision making forums has been explored '(Leeson 2007; Tarapdar 2009; Whincup 2011) there is currently less written about what happens during the day-to-day contact children have with their social workers (Ferguson 2014; Winter et al. 2015). By focusing on direct work with children looked after at home, this research contributes to the evidence base about direct work and its place within practice, and the knowledge base about children who are looked after at home.

\section{Methodology}

The research formed part of my PhD (Author, 2015), and in it I took a qualitative approach to exploring the subtleties of direct work and the constructions of meaning from the perspectives of children and professionals. Because there was less pre-existing research into day-to-day direct work, individual semi-structured interviews were chosen on the basis that the everyday may go unremarked in a survey. There is evidence that the younger the child the less likely practitioners are to engage with them (Winter 2011). With this in mind, five was chosen as the lower end of the age range for children based on the expectation that, once children are at school, they have relationships independent of their parents and therefore practitioners might reasonably be expected to have some individual contact with them. The upper end of 18 reflects the legislation which enables children to remain on Compulsory Supervision Orders until then.

After gaining ethical approval from the University Ethics Committee and visiting the local authority to meet practitioners and leave a range of information sheets for children, parents and practitioners, I held 3 focus groups to help shape my interview questions: one for children in the authority hosting the research, one for practitioners and one for managers, both of which were held outside the local authority and were comprised of professionals studying post-qualifying child protection courses where I was their tutor. The groups were attended by 2 children (one boy, one girl, both aged 14), 8 practitioners (women) and 6 managers (five women, one man). In the event the discussions were so rich, that as well as using them to inform the interview schedules, I sought and gained permission to include the data in my analysis.

Following the groups, I conducted semi-structured interviews with 6 children, 3 boys and 3 girls (6 -15 years) all of whom were recruited via their social workers, who also introduced me to children and their parents. Two children, Joe (13) and Alan $(9)^{2}$, requested that their parents be present. I also interviewed 3 team managers (men), 2 social work assistants, and 6 social workers (women) who opted to participate. All children (and their parents) completed consent forms, as did professionals. Where permission was given (all bar one teenager) interviews were taped, and I completed the transcription. As professionals introduced me to children and their parents, what I saw and heard during these interactions also constituted data. I used thematic analysis (Braun and Clark 2006; Spencer et al. 2014) to work across the data from groups, individual interviews, and my observations, and identify themes which

\footnotetext{
2 Pseudonyms are used throughout
} 
emerged. The use of the term 'emerged' could infer that I was an objective onlooker. However, as Mason (2007) argues, pure induction is difficult given that research does not take place in a vacuum. There were some themes which I expected to see and may well have looked for. However, there were others which I had not foreseen would be significant, not least the notion of compensation which I explore later.

Throughout this paper I draw on extracts from interviews to exemplify themes. One finding of existing research is that children's views have been interpreted and modified by social workers (Bruce 2014). To minimise this, I have not changed or omitted what any of the participants said, with the only exception being those instances where the manner of speech, or content might be identifiable to those who know them. However, I have selected extracts, and therefore to some extent this privileges particular parts of their accounts.

\section{What counts as direct work?}

To clarify what happened between children and social workers, a key theme for exploration was what constituted direct work. Unsurprisingly, children did not employ the term "direct work", nor did I. Rather, I asked what "happens" and what "kind of "things" they did with their social worker, and whether there was anything "you wish you could do with your social worker that doesn't happen now?" Most children said they "just talked" and while practitioners mentioned cooking, walking, going for a drive, and going to the cinema, aside from one 9 year old who described bowling with his social worker, doing figured less in children's accounts, than talking and listening. Indeed some said they wanted to "do more things" with their worker.

The need for practitioners to listen to children is set out in legislation and guidance, and being and/or feeing listened to was identified as an important aspect of direct work by all. Naomi (13) said it was "helpful to have a social worker" because "you just get to talk to them and let out your feelings". Just as children identified the importance of social workers listening and being someone to "talk to", so, too, did professionals. Lucy (social worker) commented that "I think with the kids it's about listening to them ... sitting down and listening to them, and letting them say what they've got to say". From elsewhere in her account, what also appears to underpin Lucy's comment is her sense that some children and parents have not previously felt listened to. Consequently, this is a central aspect of her direct work. Although in this study children and professionals highlighted the centrality of listening, others have found that the concept and practice of listening can be more problematic, including McLeod (2008). She found that although professionals saw listening as an action, this was not the case for young people she spoke to, and unless listening was accompanied by action young people did not feel 'listened to'.

In contrast to my interviews with children, I asked professionals what they meant by 'direct work'. I purposely did not offer any definition, but noted that there were different views, and I was interested in what they thought it encompassed with the questions "Direct work can mean different things to different people, so I just wanted to ask what you'd include as direct work" and "Can you talk me through an example of direct work". In his interview, Theo (team manager) wondered whether practitioners might limit their definition:

They sometimes see direct work as having a specific, as an hour where you sit with someone, or doing something specific and sometimes don't see that direct work maybe, 
something, a crisis developed, and you were with a young person and you had to respond to the crisis and you listen to what they tell you, but they would not see this as direct work because it's not planned.

Theo was right: some professionals only counted something as direct work if it was planned, possibly involving books, or worksheets, and produced a tangible output. However, others described direct work as "anything to do with a child", and interestingly for some the process of talking about direct work led them to review and expand their original definition. Lily (social worker), started off by saying "I don't do that much direct work" before going on to describe the range of work she undertook with children. By the end of her interview "I don't do that much" had changed to "when you break it down [...] everything you do with or for a young person is direct work".

Lily was not alone in reviewing her definition of direct work; there were several instances in individual interviews and the practitioner's group where this happened. On each occasion where talking about direct work acted as a catalyst for practitioners to review what they were doing, this always led them to identify that they were engaged in more than they initially thought, it never led them to conclude they were involved in less. Ruch (2007) highlights the place of talk in the process of reflection, and here the opportunity to talk about direct work prompted practitioners to change their perspective on the amount and quality of direct work in which they were engaged, and its value to children and their families. Pithouse (1987) characterised social work as an "invisible trade". One place where social workers make practice visible is in supervision, and thus the finding that practitioners expand their definition in dialogue with others is an important one, is relevant to the supervisory role, and the part supervision plays will be explored in another paper.

\section{Typology of direct work}

Different meanings were ascribed to direct work depending on the experiences of the child or adult. Several themes emerged as significant, with crossovers and interplays, and one way I ordered and clarified them was by developing a typology of direct work.

1) Direct work to build and sustain the relationship between child and professional, with this relationship being the foundation for assessment and intervention.

2) Direct work as part of a process of assessment.

3) Direct work as part of intervention.

\section{Direct work to build and sustain the relationship between the child and practitioner}

The message from all participants was that the relationship between a child and practitioner is fundamental. Direct work both contributes to this relationship, and is dependent on it. As with other research (Cossar et al. 2011), children situated experiences of direct work in the context of the relationship with 'their' worker, while for professionals direct work was one way they formed and sustained their relationships with children, and this relationship was presented as the foundation for assessment and intervention. Children and professionals highlighted the importance of relationship formation, or in the words of Martin (15) and Jack (14) "getting to know" each other, and for both boys this included some degree of reciprocity in terms of sharing information. In her interview Kate (social work assistant) observed that 
"when you're working with children, you have to build a relationship with them, and you have to...they have to be able to trust you, and that takes time." Kate's comments are characteristic of other professionals, and make a link between time, relationship, and trust, with the latter being associated with a willingness (on the part of the child) to share aspects of their inner life and experiences with a worker. As Susan (social worker) explained "the child will not tell you that if you don't know them [...] getting to know the child so that they feel safe enough to tell you if there's anything going on, or just how they're feeling."

\section{Direct work as part of a process of assessment}

The role of children in processes of assessment has been the subject of criticism (Laming 2003,2009 ). Rather than being at the centre, children have been found to be at the periphery (Holland 2011), and their views and experiences have not necessarily been sought, partly due to assumptions practitioners have made about the capacity of the child, or children generally (Coyne 2008, Winter 2011). In this study, professionals highlighted that direct work is one means to ensure that the child's concerns remain central. For instance several described how details which emerge during direct work as part of their assessment enable them to start to understand a child's experiences, and then tailor subsequent interventions to reflect the child's needs and interests.

More generally, practitioners gave examples where direct work had contributed towards assessment, whereas children tended not to. This may be because, as Theo (team manager) noted "the first primary job of a social worker is to assess" and so was likely to be mentioned. Several indicated that direct work might include some form of activity. Dependent on the weather and location, golf, football, sledging and going for a walk were mentioned to get to know a child in a way which Mara (social worker) described as more "natural". When inside (including cars) professionals recalled using books, toys, or drawing to enable children to talk about their experiences and feelings. Several identified how direct work helped them to differentiate between how a child presents externally, and is seen by others, and how they view themselves.

Direct work was one means professionals used to help them assess particular risks and strengths within the child's environment. Some described using the "bag of worries" (Ironside 2004), the weight of which can be reduced if worries are shared, to enable children to talk about their concerns. Kate (social work assistant) explained that she used this approach to help one ten year old girl name her concern that as a consequence of alcohol misuse her mother would "not wake up". Claire (social work assistant) used drawings to help assess the potential risks an eight year old girl was exposed to when visiting family:

There was one girl, and we needed to know whether she was visiting her grandparents and what she was doing [...] there were two schedule one offenders ${ }^{3}[. .$.$] The mother$ went where the child went, this was what the mother was telling us. But we needed to find out whether, uh, that was happening from the child. And the child sat with a worksheet about the house and we worked through, this is gran's house, and we started to draw. I

\footnotetext{
${ }^{3}$ Schedule 1 of the Criminal Procedures (Scotland) Act 1995 sets out offences against a child including, as in this instance, sexual offences.
} 
had the same as what the child had and I would say, "Oh I've got this bedroom", and the child said "Oh this is my uncle's room", she said, "But l'm not allowed to go in there". But in saying that she knew what was in the room (Claire).

For Claire, direct work helped her to build a picture different to that presented by family members, namely that although the girl was not supposed to have access to her uncle's room, she could recall what was in there. Children in the study tended not to comment on the link between direct work and assessment; however Martin's comments are cautionary. After saying to Martin (15) that I was interested in what people do with their social worker, there was the following exchange:

Martin: Ask questions

Int: So you'd ask him (Don) questions and he'd ask you questions?

Martin: Nah, he'd ask me questions...he'd use big words and then he'd ask me questions.

He confirmed that his current worker took a similar approach.

Int: Okay... and what about you and Mary, what do you guys do?

Martin: She just asks me questions, just asks me how I am and about the house and stuff like that.

Earlier I referred to McLeod (2008) who identified a dissonance between social workers' accounts of the ways they listened, and how this was experienced by children. I wonder if there was a similar process here. It is possible that practitioners were endeavouring to place Martin at the centre of an assessment process; however this was experienced by Martin as "asking questions" using "big words".

\section{Direct work as intervention}

Davies and Ward (2012) propose that effective interventions include different domains: child focused; parent focused; child and parent focused; family focused. Children gave examples of all four, but tended to concentrate on interventions with them or their parents.

Professionals cited examples across all domains; however I will focus on interventions with children of which there were five interconnected sub-themes: direct work designed to maintain a child's developmental needs; work to reduce risk, thereby protecting the child; reparative interventions aimed at repairing relationships and/or the child's view of themselves; direct work which is compensatory; work which is preparatory, including preparing a child to engage in decision making forums. These five sub-themes have commonalities with, and build on four areas previously identified by Gilligan (1999).

\section{Maintain development}

There were instances where direct work could be seen as maintaining a range of developmental needs. Joe and his parents described how Joe's social worker had been instrumental in arranging educational support outside mainstream school, which helped his educational and social development, while Jim (Alan's father) credited Alan's social worker Sally with making a difference to the place education plays in his son's life. Jim's comment 
that "he seems to be a far happier boy" appears to suggest she has contributed to a change in Alan's overall sense of well-being:

At the Hearing I actually requested that they keep Alan on the supervision order so that he could be around Sally a bit longer and that gives me time to get my act in order, and he hasnae been off the school, just once when they sent him home, and he's handing his homework in. He seems to be a far happier boy than he was before (Jim).

In common with other studies (Osmond and O'Connor 2004; Gordon and Cooper 2010) it was unusual for professionals to mention theory. However, attachment theory was referenced sometimes explicitly, but more often obliquely, to explain difficulties children were experiencing and what underpinned direct work. Although Mara does not reference the central significance of a coherent story (Fahlberg 1994; Daniel et al. 2010) to development, this could be read as the purpose of her work with a 12 year old boy Ben who, amongst other things, is negotiating a path between different people in his life:

Ben sort of boxes things in his life. It's like the foster placement is separate from mum, is a separate issue from school, dad is a separate issue, and it's really like little cubes for him, and he wouldn't for example talk about his foster placement when he's with mum, or talking about his mum when he's in the foster placement. Usually the travel is the transition period, we are moving from one to another, so it's really about telling him that, you know, it's, it's really okay to mix those[...]So, it's like linking those little cubes for him in his head and I think that's the most important part for him (Mara, social worker).

The car as a locus of direct work has been identified in literature and existing research (Ferguson 2010) and was mentioned in several interviews. Mara described how she used the "transition period" in the car to help Ben make links between different aspects: to talk about grief and the death of his grandfather; to consider parental responsibilities and rights; to enable him to express his feelings within the context of complex, and at times conflictual, relationships between the adults around him. For Mara, although each of these aspects were important in maintaining development, the principal meaning she ascribed to her work was that it would help Ben by "linking those cubes for him in his head", in other words, to help him develop a coherent and integrated story.

\section{Interventions to protect}

Earlier, I drew on an extract from a social work assistant who described how using drawings enabled her to get a clearer sense of the contact a child had with an uncle who posed a risk. As is to be expected given their role, most professionals described one aim of direct work as protection. Similarly, for children, this also emerged as an important facet as can be seen from the following comments from sisters Josie (9) and Reanne (6):

Int: What do you think you two get from seeing Caroline, what difference do you think it has made?

Josie: Well, my mum (pause). Caroline helping my mum has made, maybe this a safer place, it feels safer to be in.

Int: Right, Caroline helping your mum has made home safer?

Josie: Uh, huh, feels safer. 
Int: And can I ask you both, if you didn't feel safe at home, who would you tell?

Josie: Caroline.

Reanne: Caroline.

For Josie and Reanne, what emerges here and elsewhere in their interview is that feeling "safer" appears to be linked to several factors. It includes the direct work their social worker Caroline has undertaken with their mother, including encouraging her to use less rigid disciplinary measures. Caroline's presence as someone to whom they can contact and speak to also appears to contribute to their sense of being protected, as later in the interview Josie comments "If you're ever worried there's someone there for you".

Direct work which is reparative

Direct work aimed at repairing relationships within a child's family emerged as a key theme with managers and practitioners describing examples, as did children. Joe (13) was interviewed with his parents Audrey and Neil present, and all mentioned that direct work on "rules" and "discipline" had been important to them as a family. The following conversation was in response to my question about what Joe had "got" from social work contact:

Audrey: More discipline.

Joe: There wasnae any.

Audrey: For me to put more discipline in place.

Neil: More structure.

Joe: Like if I got brung home by the police.

Audrey: It was the whole family.

For Joe, Audrey and Neil, the process of agreeing boundaries with their social worker, and introducing new rules, helped repair relationships and reduced conflict. In addition to looking at routines and rules, professionals' accounts included encouraging children and parent(s) to read, play, or cook together to repair or re-build relationships by enjoying the time they spent together. Earlier I noted that the theory underpinning intervention generally remained tacit. In the following extract, while Claire does not explore her understanding of attachment theory in depth, she does make reference to it, when she explains that "there wasn't really an attachment" to preface why she was involved with two boys and their mother. Although she employs the adverb "simply", Claire's intervention was anything but simple, and was designed to be reparative on different levels:

I had one family (laughs) and there were two boys, and there was a lot of, there were behaviour problems with both boys. One was really quite bright, but had a lot of behavioural problems too. We kind of thought it was to do with the attachment, there wasn't really an attachment with mum and both the boys. And I can remember going there and just simply cooking with mum and the boys. They enjoyed that. They really wanted to do something with mum, and one of the boys, the oldest one, he sort of had a... food was a sort of survival for him. When he was stressed he would eat, and you could notice that 
with him, but doing the cooking was just relaxing and he was able to... The other thing we did with them I took photographs. So we did that and we got prints made for the boys and for mum. And it was giving them something happy in their life that we did this with mum (Claire, social work assistant).

There is existing research on the role food plays both in building and maintaining relationships at home and within residential child care (Punch et al. 2011). Crucially, by Claire encouraging them to cook together, food, which for this family had become both an indicator of trauma and an area of conflict, could start to be viewed as something which might be utilised to repair relationships.

In addition to direct work as one means of repairing relationships with parents, peers, or siblings, some professionals identified that the aim was to counter the impact of the child's previous experience of social workers and social work processes, and thus was also reparative. There is evidence that exclusion from decision-making forums can be detrimental to the development of self-efficacy (Leeson 2007). However, being present does not guarantee meaningful participation, and a child's right to attend does not necessarily mean it is in their interest to do so. Professionals in this study identified that for some children who attended formal meetings, not only had they not participated, but they had emerged with an inaccurate, and in some instances damaging, version of where the responsibility for change lay. For some practitioners, their role after meetings was to undo the impact on a child of attending. For others, their aim was to repair or "redress" the negative legacy of a previous worker as Janie highlights:

The other part for the young person is that her history is that she made a couple of allegations that her dad sexually abused her and unfortunately the previous worker didn't believe her and wrote quite judgemental things about her and her behaviours and I felt quite responsible to redress a lot of that. And I started by re-writing [...] I went from scratch with this young person's report and re-worded things so that it had a different slant and explanations for behaviours, uhm, and made a point of allowing the young person to see the report which had been written previously and to see the report that I had written to redress that (Janie, social worker).

There is evidence that contrary to guidance, children are not always provided with opportunities to read reports. When they do, the language used can exclude them, and there are indications that similar to the young person with whom Janie was working, children's accounts are disbelieved or devalued, and they may internalise negative descriptions and incorporate these into their view of themselves (Tucker 2011; Cossar et al. 2011). For Janie, re-writing the report and sharing this was reparative, and was part of building a trusting relationship.

\section{Direct work to prepare children}

Professionals recalled instances of direct work which could be described as preparatory, with two strands dominating: direct work to prepare a child for transition, including prior to major life changes; or direct work with a child and or parents to prepare for formal meetings to facilitate their participation. Susan (social worker) recalled how she initially had contact with a boy while he was in his birth family, but after accommodating him the focus changed. 
Here, she explains how direct work was central in preparing him for the move to his permanent alternative family:

Every week I spent an afternoon with him, looking at moving on from his old family, what kind of families were out there[...] getting him to a stage that when it came that we had found an adoptive family for him, that he was ready then to move on and just to help him deal with... unhappy memories from the past and just to give him a space to talk [...] It was really just about trying to get things right for him for the rest of his life 'cos you were, in actual fact you were changing everything about his life (Susan).

Susan used direct work as part of the process of preparing the boy to move to a permanent placement, to help him to be "ready" to move and later expresses the view that unless "that part of it is right", there is a danger that the placement would not be successful. Other professionals recalled how they used direct work to prepare children and their parents to participate in decision-making forums. This included reading through reports, and giving information about processes, and what was likely to happen. However, as discussed earlier, several cited examples where direct work was designed to be reparative by ameliorating the impact of attending formal meetings, and presumably this is uppermost in Lily's mind when she comments:

You can prepare them as much as you can for a Hearing but sometimes when you get there they are not prepared even though you have put that time in with them. I think it can still be a very daunting process for any child (Lily, social worker).

\section{Direct work as compensatory}

I was not surprised by some of the themes which emerged, including the importance of protection and the centrality of relationship. However, the idea that direct work might compensate for areas which practitioners viewed as missing from a child's life was not something I had anticipated would emerge to the extent it did. The sense that direct work was compensatory was present to a greater or lesser degree in seven out of the eleven interviews with professionals, and the managers' reference group. Although references to compensation were usually tacit, practitioners appeared to conceptualise compensation in interconnected but distinct ways. Direct work was presented as providing access to discrete activities or experiences a child might not have had as a consequence of limited family finances or parental disinclination; it was also presented as compensating for negative experiences or deficits, particularly in the child's relationships with their parent(s). Lucy recalled how as part of her work with a teenage boy, she had taken him shopping and there is a sense that the time she spent with him is compensating for day-to-day experiences which she would ordinarily expect to have been provided by his "mum and dad":

We would go shopping and we went and we bought wee... like you would do with your mum and dad, like you would do with somebody, anybody, he's never done that before, ever in his life (Lucy, social worker).

Although they talked warmly about their time spent with children, it was evident that professionals shared a sense of regret and sadness that children had missed out on experiences which the professionals constructed as normative. Some also expressed ambivalence about how effective this aspect of direct work was, particularly when deficits in 
the parent/child relationship remained. This was most candidly articulated by Sara in the group for team managers:

It's something l've thought about is when l've spent time playing with a child, whatever, and then its...kind of giving them something and then taking that away[...]I'm not going to be there to play with them every week forever, and it's been a good time, whatever, and then it's like, well that's over...now your parent doesn't play with you and I've not managed to change that (Sara, team manager).

Interestingly, none of the children appeared to identify that their contact with social workers was, or could be, compensatory, although the closest was Naomi (13) whose comment that if she "didn't have Maud or Sarah, I wouldn't have talked to anyone about what happened" appears to infer that social work professionals fulfilled an important role, which would otherwise have been absent. One critique of social work practice is that it focuses on deficits and risks, and underestimates the strengths and capacities which children, their parents and networks bring (Turnell and Edwards 1999). It may be that when practitioners framed their interventions, albeit tacitly, as compensatory, this can be contextualised within an approach which focuses on deficits, rather than strengths. It may also be that practitioners had a sense of the rationale of direct work, but had not made this explicit to children, and consequently compensation did not emerge within children's interviews as a theme. Additionally, it may be that practitioners were willing to identify deficits in a child's experience, whereas children may not have done so in the context of a research interview.

\section{Discussion}

The study was relatively small, and all participants opted-in, with children recruited through their social workers. The experiences they shared are not necessarily representative of other children in the local authority, or more generally, and a similar qualification applies to the professionals. Notwithstanding this proviso, their experiences contribute to an understanding of what happens when children and social workers are together, and what direct work looks like for some children, and some professionals.

There are studies which explore how practice is enacted and what social workers do (Ferguson 2014). However, there is more written about what social workers are prevented from doing, or are not doing. In a discourse which tends to focus on deficits, it can be difficult for practitioners to acknowledge that direct work happens. In part, this may be in case this implies the practitioner's caseload is not sufficiently taxing. This paper has explored some of the everyday exchanges between children and social workers, and the tacit and explicit meanings ascribed to direct work and has built on the work of Gilligan (1999) to suggest a typology of direct work which encompasses intervention and assessment. In doing so it challenges the view that social workers cannot, and/or do not engage in meaningful, and sensitive direct work, as it is evident that despite other calls on their time, some very clearly can and do.

It is of interest that several professionals initially underestimated the amount and value of direct work. Having the opportunity to talk about direct work prompted them to expand their definitions of direct work, how much they were doing, and its value. This is an important finding, and suggests that unless practitioners are offered opportunities to explore direct 
work, within the context of practice, there is the risk that the amount and value of direct work in which they are engaged may go unnoticed or unrecognised.

\section{References}

Baginsky, M., Moriarty, J., Manthorpe, J., Stevens, M., Maclnnes, T. and Nagendran, T. (2010) Social Work Task Force, Social Workers' Workload Survey: Messages from the Frontline, Findings from the 2009 Survey and Interviews with Senior Managers' London: Children's Workforce Development Council (CWDC), King's College, University of London, New Policy Institute.

Braun, V. and Clarke, V. (2006) Using thematic analysis in psychology. Qualitative Research in Psychology, 3, pp.77-101.

Bruce, M. (2014) The Voice of the Child in Child Protection: Whose Voice? Social Sciences, 3 (3), pp.514-526.

Butler, I. and Williamson, H. (1994) Children Speak: Children, Trauma, and Social Work. Essex: NSPCC, Longman.

Bryman, A. (2008) Social Research Methods. 3rd Ed. Oxford: Oxford University Press.

Children (Scotland) Act 1995, London: HMSO.

Children's Hearing (Scotland) Act 2011, UK: The Stationery Office.

Cossar, J., Brandon, M. and Jordan, P. (2011) 'Don't make assumptions': Children's and young people's views of the child protection system and messages for change. Office of the Children's Commissioner. Available:

http://www.childrenscommissioner.gov.uk/content/publications/content 486

Coyne, I. (2008) Children's participation in consultations and decision making at health service level: A review of the literature. International Journal of Nursing Studies, 45 (11), pp.1682-1689.

Daniel, B., Wassell, S. and Gilligan, R. (2010) Child Development for Child Care and Protection Workers. 2nd Ed. London: Jessica Kingsley Publishers

Davies, C. and Ward, H. (2012) Safeguarding Children Across Services: Messages from Research. London: Jessica Kingsley Publishers.

Emond, R., Steckley,L., Roesch-Marsh, A.(2016) A Guide to Therapeutic Child Care: What You Need to Know to Create a Healing Home. London: Jessica Kingsley

Fahlberg, V. (1994) A Child's Journey through Placement. London: BAAF.

Ferguson, H. (2010) Therapeutic journeys: the car as a vehicle for working with children and families and theorising practice. Journal of Social Work Practice, 24 (2), pp.121-138. 
Ferguson, H. (2014) What social workers do in performing child protection work: evidence from research into face-to-face practice. Child \& Family Social Work, Early View, March 2014. Available:

http://onlinelibrary.wiley.com/doi/10.1111/cfs.12142/abstract

Gadda, A. (2012) Looking after young people? An exploratory study of Home Supervision Requirements. Ph.D., University of Edinburgh, School of Social and Political Sciences.

Gilligan, R. (1999) Enhancing the resilience of children and young people in public care by mentoring their talents and interests. Child \& Family Social Work, 4 (3), pp.187-196.

Gordon, J. and Cooper, B. (2010) Talking Knowledge - practicing knowledge: A critical best practice approach to how social workers understand and use knowledge in practice. Practice: Social Work in Action, 22 (4), pp.245-257.

Henderson, G. and Whitehead, I. (2013) How much is Education included in the plans of Children on Supervision Requirements. Scottish Children's Reporter Administration. Available:

http://www.scra.gov.uk/cms resources/SCRA\%20Research\%20Report\%20\%20Education\%20and\%20SRs\%20-\%20March\%202013.pdf.

Holland, S. (2011) Child and Family Assessment in Social Work Practice. London: Sage Publications.

Ironside, V. (2004) The Huge Bag of Worries. London: Hachette Publishing.

Laming, Lord. (2003) The Victoria Climbié Inquiry Report. Norwich: The Stationery Office.

Laming, Lord. (2009) The Protection of Children in England: A Progress Report. London: The Stationery Office.

Leeson, C. (2007) My life in care: experiences of non-participation in decision making processes. Child \& Family Social Work, 12 (3), pp.268-277.

Lefevre, M. (2008) Knowing, being and doing: Core qualities and skills for working with children and young people in care. In B. Luckock and M. Lefevre Eds. (2008) Direct Work: Social work with children and young people in care. London: BAAF, pp.21-39.

Mason, J. (2007) Qualitative Researching. 2nd Ed. London: Sage.

McLeod, A. (2008) Listening to Children: A Practitioner's Guide. London: Jessica Kingsley

Munro, E. (2011) The Munro review of child protection, final report: a child-centred system. London: The Stationery Office.

Osmond, J. and O'Connor, I. (2004) Formalizing the Unformalized: Practitioners Communication of Knowledge in Practice. British Journal of Social Work, 34 (5), pp.677-692. 
Pithouse, A. (1987) Social Work: The Social Organisation of an Invisible Trade. Aldershot: Avebury Press

Punch, S., Mclntosh, I. and Emond, R. (2011) eds. Children's Food Practices in Families and Institutions. London: Routledge

Ritchie, J., Lewis, J., McNaughton Nicholls, C. and Ormston, R. eds. (2014) Qualitative Research Practice, 2nd Ed. London: Sage.

Ruch, G. (2007) Reflective Practice in Contemporary Child Care Social Work: The Role of Containment. British Journal of Social Work, 37 (4), pp.659-680.

Scottish Children's Reporters Administration (2015) Statistical Analysis 2014-2015 Online Statistics and Local Authority breakdown. www.scra.gov.uk

Scottish Executive (2006) Changing Lives: Report of the 21st Century Social Work Review. Edinburgh: Scottish Executive. Available:

http://www.gov.scot/resource/doc/91931/0021949.pdf

Spencer, L., Ritchie, J., Ormston, R., O'Connor, W., Barnard, M. (2014) Analysis:

Principles and Processes, Chapter 10, pages 269-293. In: J. Ritchie, J. Lewis, C. McNaughton Nicholls, R. Ormston, eds. Qualitative Research Practice: A Guide for Social Science Students and Researchers. 2nd Ed, London, Sage.

Tait, A. and Wosu, H. (2013) Direct Work with Vulnerable Children: Playful Activities and Strategies for Communication. London: Jessica Kingsley

Tait, A. and Wosu, H. (2016) Direct work with Family Groups: Simple, Fun Ideas to Aid Engagement and Assessment and Enable Positive Change, London: Jessica Kingsley

Tarapdar, S. (2009) I don't think people know enough about me and they don't care: Understanding and exploring the needs of young carers from their perspective, Available: http://www.open.ac.uk/ccig/files/ccig/TARAPDAR,\%20Saima\%20\%20Presentation 0.pdf

Tucker, S. (2011) Listening and Believing: An Examination of Young People's Perceptions of why they are not Believed by Professionals when they Report Abuse and Neglect. Children \& Society, 25 (6), pp.458-469.

Turnell, A. and Edwards, S. (1999) Signs of safety: A Solutions and Safety Oriented Approach to Child Protection Casework. London: W.W.Norton \& Company.

Whincup, H. (2011) Involving children and young people in assessment and decision making. Scottish Child Care and Protection Network. Available:

www.withscotland.org.uk

Winter, K. (2011) Building Relationships and Communicating with Young Children: A Practical Guide for Social Workers. London: Routledge, Taylor \& Francis Group. 
Winter, K. (2015) Supporting positive relationships for children and young people who have experience of care. Glasgow: IRISS. Available:

http://www.iriss.org.uk/sites/default/files/iriss-insight28-020315.pdf 
